\title{
Realizing the Potential of Nanotechnology for Agriculture and Food Technology
}

Sudesh Kumar Yadav ${ }^{*}$

Center of Innovative and Applied Bioprocessing (CIAB), Mohali, Punjab, India

*Corresponding author: Sudesh Kumar Yadav, Center of Innovative and Applied Bioprocessing (CIAB), Mohali, Punjab, India, Tel: +91 172 4990216; E-mail: sudhirsingh@ciab.res.in

Received date: February 17, 2017; Accepted date: March 01, 2017; Published date: March 10, 2017

Copyright: (c) 2017 Yadav SK. This is an open-access article distributed under the terms of the Creative Commons Attribution License, which permits unrestricted use, distribution, and reproduction in any medium, provided the original author and source are credited.

\section{Abstract}

Nanotechnology is one of the most promising tools for the current revolution in agri-food sector. Nanotechnology approaches provide novel and innovative ways to improve crop yield and to reduce the use of harmful crop protection agents. Nanotechnology can be useful for biotic and abiotic stress tolerance of plants, lesser use of pesticides/insecticides/herbicides, nanosensors for crop protection from bacteria, disease treatment, pest control management and genetic manipulations by nano delivery vehicles. Also, nanotechnology has great advantages in food sector like detection of pesticides/toxicants in food items, development of food storage and packaging materials, enhancement of shelf life of foods, nanoencapsulation of food nutraceuticals or bioactive molecules, detection of pathogens in food materials, enhancement of food taste, color and odour. Above all, safety concerns regarding the use of nanomaterials should be of priority before their exploration for positive impact on agriculture and food.

Keywords: Nanotechnology; Agriculture; Nanoparticles

\section{Introduction}

Nanotechnology, a recently developed field of science which could even fit into a person's fingernail is mainly an inter-disciplinary branch of physics, chemistry, biology and engineering sciences, rapidly growing to radically transform electronics, automobiles, agriculture, food and various other industrial systems. Nanomaterials/ nanostructures with unique physical, chemical and mechanical properties can be synthesized by applying this attractive technology which may find applications in industrial sectors of global market. Synthesized nanomaterials are characterized by high end equipments SEM, TEM, AFM, DLS zeta, X-ray diffraction, DSC, TGA, fluorescence, FT-IR and UV-Vis spectroscopy for their morphology and other attributes like size, stability, surface charge, degree of crystallinity, presence of surface functional groups, and thermo sensitivity.

This technology has already brought revolution in wide spectra of life and provides a frontier platform for the development of products and technologies suitable for agriculture and food sector. Scientists and industry stakeholders are spearheading towards the use of nanotechnology in agriculture and food science starting from crop/ food cultivation, production, processing, and up to packaging. I strongly feel that nanotechnological tools can be used to build up new extremes having an impact of new incredibly tiny particles on several aspects of food science. But our ability to reap the long-term benefits of nanotechnology in areas from agriculture, food nutraceuticals to medicinal pharmaceuticals will depend on how well industry and government manage the safety and performance of this generation products. Because of potential applications in food, agriculture and health care sector, government is investing billions of dollars in nanotechnological research. In fact, its impact is already visible in terms of the research being conducted throughout the world. Nanotechnology seems promising towards eliminating the sufferings and problems being faced by society such as climate change, population growth, limited availability of nutrients, pest/insect attack, post-harvest, and food processing losses.

\section{Nanotechnology in Agriculture}

Agriculture is the back bone of national economy in developing countries like India. Today the foremost challenges faced by the world agriculture are the climatic changes, high urbanization, runoff and accumulation of pesticides, insecticides and fertilizers. Troubles are further intensified by an alarming rise of food demand to satisfactorily meet the feeding needs of an estimated population of 6-9 billion by 2050. The conventional technologies developed so far in the agriculture field are not worth in resolving the existing problems and are unable to increase the food productivity. For developing countries, advancement in science and technology can offer potential solutions for discovering value addition in their current production systems. Nanotechnology approaches applied to agricultural production could play an essential role for this rationale. Nanotechnology in agriculture can be aimed at to trim down the use of products for plant protection, minimize nutrient losses, and increase yields through genetic improvement of plants and optimized nutrient management methods. Nanomaterials need to be explored for positive changes in agriculture sector by effective delivery of genes at specific location in the cellular system [1]. Nanoparticles/nanovehicles can act as 'magical bullets' to entrap herbicides, chemicals, or genes of interest, and their sustained release. Nanoformulations and nanocapsules can facilitate improved absorption, solubility, stability and help in successful penetration of herbicides through cuticles and tissues, allowing controlled release of the active substrates (Figure 1). The controlled and slow release of herbicides/fertilizers by nanoformulations will lower down their dose and minimize environmental pollution [2]. Nanoarray-based genetechnologies need to be developed for altering the gene expressions of plants so as to bring them in active growth mode even during the dormant phase or stress conditions. This new technology can be 
effectively used to devise sensitive nano sensors for the detection of pathogen and detection of pesticide residues in crops.

Towards this effort, we have developed a novel approach for the green synthesis of biodegradable polymeric PLA (poly-D,L-lactide) nanoparticles encapsulated quercetin for improving the shelf life of tomatoes. This approach could also be used to improve the shelf life of various fruits and vegetables and hence, can turn out to be a boon for both the farmers as well as consumers. Another effort in the agro sector was put forward to induce the growth and yield enhancements of Arabidopsis thaliana by the exposure of gold nanoparticles. Gold nanoparticles can serve as promising tool to increase the seed yields of plants [3]. Currently, we are dealing with the isolation of cellulose nanocrystals from the leaves/biowastes of plants. These cellulose nanocrystals can also be used to develop nanocomposites that may be beneficial as nano-matrix for prospective applications in agriculture for the delivery of micro-nutrients, vitamins and bioactives, and also for pesticide absorption. We have also developed the methodologies for biological synthesis of gold and silver nanoparticles. Such green metallic nanoparticles may play a detrimental role in disease management of plants as they possess wide spectra of anti-microbial activity. Cellulose nanocrystals with high water uptake potential can be explored for effective seed germination. Mesoporous silica nanoparticles (MSNs) can deliver DNA and chemicals into plant cells and intact leaves. MSNs may offer new possibilities in target-specific delivery of proteins, nucleotides and chemicals in plant biotechnology [4] (Table 1).

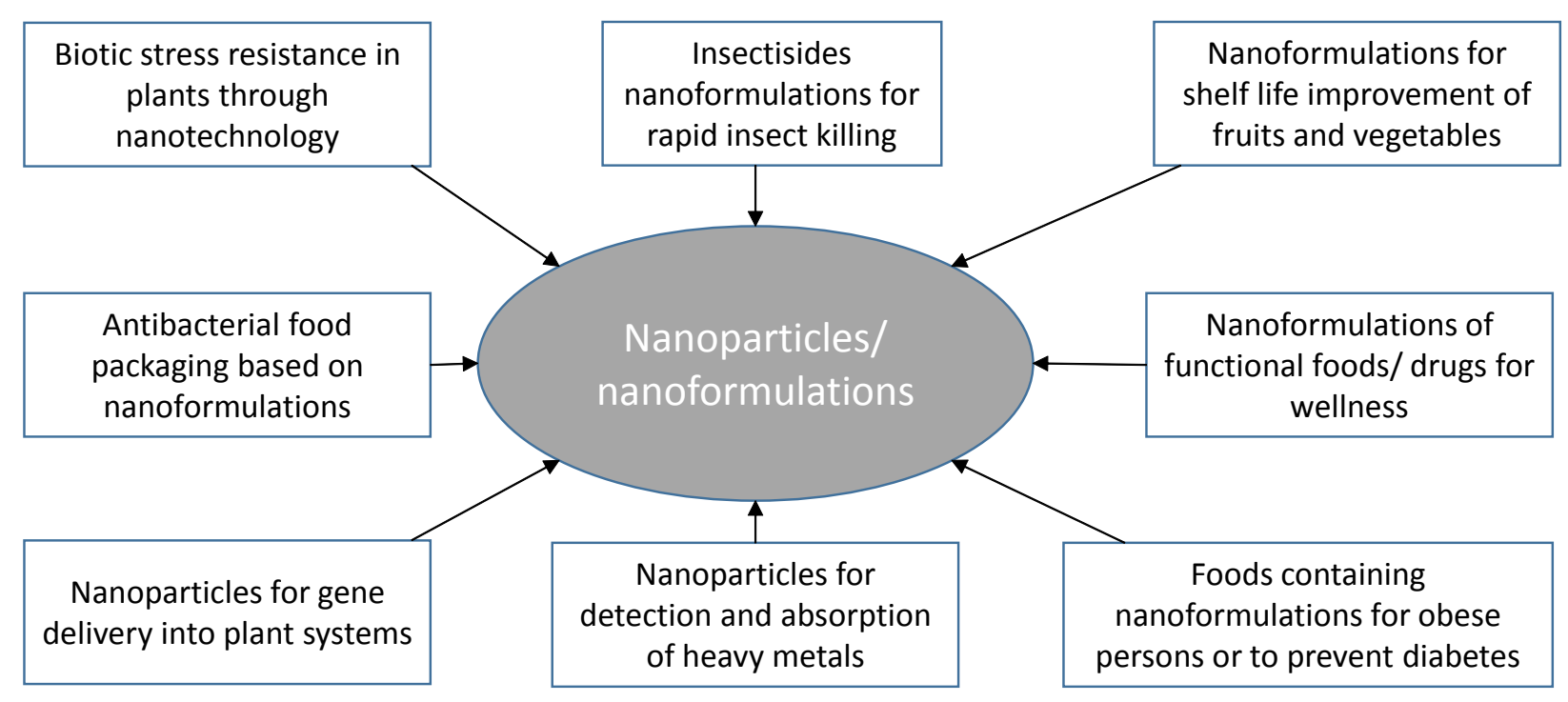

Figure 1: Applications of nanotechnology in agriculture and food sectors.

\section{Nanotechnology in Food}

The term 'nanofood' basically deals with the food that has been cultivated, produced, processed and then packed using various nanotechnological aspects or the food in which synthesized nanomaterials have been added. The nanoformulation of the dietary supplements, functional foods, bioactive molecules, and herbal products having medical value is known as nano-nutraceuticals, a term combining nutrition with pharmaceuticals. Food items undergo a variety of modifications at the stage of post-harvesting and processing that bring a change in the biological and biochemical makeup of food. Hence, the nanotechnological advancements in the fields of biology and biochemistry could influence the food industry.

The existence of bioactives in food as nutraceuticals has excellent tendency to provide physiological benefits and to reduce the risks associated with the diseases for humankind. However, effectiveness of many of these bioactives is limited due to their lesser bioavailability, poor solubility and stability inside the gut, lower retention time in gastro-intestinal tract and permeability. It has been a challenge and overwhelming task for the scientists engaged with nanotechnology to overcome these limitations. Companies are now developing novel functional foods with improved taste and health benefits. Hence, nanotechnology can be a promising technology to resolve the issues related to food security, shelf life, disease treatment, delivery methods, detection of food contaminants and pathogen, food packaging and protection of the environmental contamination.

In food sector, nanotechnology can be applied in two different approaches, i.e., 'top down' and 'bottom up'. Large surface area per unit mass of nanomaterials has an influence to increase the biological activity of molecules. Reduced particles dimension would provide better bioavailability, delivery properties, and solubility. Nanoencapsulation, targeted delivery and controlled release of nutraceuticals, or functional food ingredients, food processing and food packaging are the major applications where nanotechnology can be applied to promote food industry. Nanoencapsulation is one of the most feasible methods to entrap bioactive molecules. Various nutrients are indispensable for well-being, and can facilitate us to maintain a strong immunity. Bioactives with poor aqueous solubility, bioavailability and stability under physiological conditions belonging to vitamins, anti-oxidants, food ingredients, micronutrients, and polyphenols can be encapsulated in nanoformulations. Nanoencapsulation will enhance the bioavailability and biodistribution of bioactives [5]. Based on requirement various types of encapsulations nanospheres, nanoparticles, nanoemulsions, nano-cochleates, micelles and liposomes can be made. 
Our research group has recently encapsulated curcumin and quercetin in PLA nanoparticles using turmeric extract as biostabilizer. A novel greener approach has been developed to encapsulate bioactives in PLA nanoparticles using plant leaf extract [6-8]. These nanoencapsulated molecules can be used as food nutraceuticals as they possess strong anti-oxidant and anti-disease activity. Stevioside nanoparticles have also been prepared to develop antidiabetic nutraceuticals [9]. Podophyllotoxin and etoposide encapsulated in PLA nanoparticles were also synthesized [10]. Tea polyphenols, catechin and epicatechin were encapsulated in BSA nanoparticles to enhance their stability and bioavailability [11]. The nanoformulations of these bioactives showed sustained release, maintained their antioxidant potential and improved efficacy. This has suggested their better and effective use for mankind.
We have synthesized gold nanoparticles and silver nanoparticles using leaf and seed extracts of different plants such as Syzygium cumini, Lonicera japonica, Bauhinia variegate [12-16]. Gold and silver nanoparticles are anti-bacterial in nature and therefore, can be used in the development of food packaging materials. They can also be used to devise nanosensors for the detection of pesticides and bacteria such as Salmonella, E. coli in the food items. The cellulose nanocrystals impregnated with silver nanoparticles can also be used for food packaging. These cellulose nanofibers can be used to immobilize enzymes, vitamins for betterment of food products. The cellulose nanofibers can act as nanovehicles for controlled and targeted delivery of nutraceuticals.

\begin{tabular}{|c|c|c|c|}
\hline Sr. no. & Types of nanomaterials & Function/property & Applications \\
\hline 1 & Gold nanoparticles & $\begin{array}{l}\text { Fluorescence, anti-bacterial } \\
\text { nature, SERS effect }\end{array}$ & $\begin{array}{l}\text { Used in nanosensors for detection of pesticides in water, gold nanoparticles attached with } \\
\text { nanomatrix can be used for absorption of pesticides, used in development of food packaging } \\
\text { materials, can induce plant growth and yield, help in detection of bacteria in food samples }\end{array}$ \\
\hline 2 & Silver nanoparticles & $\begin{array}{l}\text { Surface plasmon resonance, } \\
\text { anti-microbial nature, }\end{array}$ & $\begin{array}{l}\text { Used in food packaging, filtration media, pesticide detection and absorption, larvicidal and } \\
\text { antifouling nature of silver can be used in agriculture to prevent foul smell in stagnant waters. }\end{array}$ \\
\hline 3 & Quantum dots & Fluorescent property & Used to detect food borne pathogen and toxicants \\
\hline 4 & Cellulose nanocrystals & $\begin{array}{l}\text { High water uptake capacity, } \\
\text { biocompatible }\end{array}$ & $\begin{array}{l}\text { Can be used in food packaging, development of nanocomposites, for enhancing seed } \\
\text { germination, immobilization of enzymes, vitamins and minerals and their delivery to target } \\
\text { plant part, used in absorption of heavy metal ions in water }\end{array}$ \\
\hline 5 & Magnetic nanoparticles & Large specific surface area & $\begin{array}{l}\text { Gene delivery, plant disease diagnostics, removal of heavy metals, food analysis, enzyme } \\
\text { immobilization, protein purification, pathogen monitoring }\end{array}$ \\
\hline 6 & Polymeric nanoparticles & $\begin{array}{l}\text { Biodegradable nature, ease } \\
\text { of surface modification }\end{array}$ & $\begin{array}{l}\text { Development of nanoformulations of pesticides, fertilizers, food additives, bioactive } \\
\text { molecules, nutraceuticals and phytochemicals }\end{array}$ \\
\hline 7 & Carbon nanotubes & $\begin{array}{l}\text { Optical, electrical and } \\
\text { mechanical properties, } \\
\text { thermal conductivity }\end{array}$ & $\begin{array}{l}\text { Used in delivery of pesticides, fertilizers and other chemicals, can penetrate the membrane, } \\
\text { act as plant growth modulators, can stimulate seed germination, can enhance water and ionic } \\
\text { nutrients, used in food inspection and vacuum proof food packaging }\end{array}$ \\
\hline
\end{tabular}

Table 1: List of nanomaterials along with their applications in agriculture and food technology.

\section{Safety Concerns and Regulatory Laws}

Since the properties of nano-structures change with the change in method of synthesis, encapsulation materials, dimensions and shape, risks associated with the use of such materials are of major concern. Sometimes, the developed nanoformulations may be toxic to the plants and animals. There are no standard regulatory laws or guidelines developed for describing the use of nanomaterials in agriculture and food sectors. Hence there is strong need to develop certain guidelines and policies for the safer use of nanostructures.

\section{Conclusion and Future Perspectives}

Nanotechnology can bring a revolution in the field of agriculture and food technology with the great efforts and understanding of people engaged in this daunting challenge starting from the agriculture fields for food cultivation upto the food consumer market. The properties of nanoformulations are different from the bulk materials which are beneficial for the progress of nation to overcome the existing problems. But there is a safety and toxicity concern over the use of these nanoformulations at a particular dosage. Certain standards of regulatory laws should be framed to describe the guidelines for the use of nanomaterials about their safety and toxicity so as to bring nanotechnology at the top front in the global world especially in agrifood sector. To achieve this, research teams need to be multidisciplinary to find innovative solutions to meet the demand of growing population as well as their better life. The possible future perspectives in agri-food technology are framed on the basis of "use less but gain more" as:

- Development of some new nanotechnological methods and nanocomposites of food grade substances/biomolecules (plant or microbial origin) with surface/gene modifications so that they can play the dual role to protect the plant from any kind of stress and increase its production.

- $\quad$ Exploration of more bioactive molecules and improvement in their effective use through nanotechnology

- Genetic modification through nanotechnological approaches to protect the plants from biotic and abiotic stress.

- Designing of handy instruments or nano-devices to determine the amount of heavy metal ions, and pesticide residues in agricultural land.

- Cytotoxicity of nanomaterials should be assessed so as to decide the safety dosage of nano foods. 
Citation: Yadav SK (2017) Realizing the Potential of Nanotechnology for Agriculture and Food Technology. J Tissue Sci Eng 8: 195. doi:

Page 4 of 4

- Efforts can also be made to study the effect of nanoparticle size and shape on the nutritional values because the properties of materials changes with the alteration in dimensions/surface modifications.

- In vivo studies in live animal models should be carried out to check the bio-distribution, efficacy and mechanism of action of biomolecules of some newly constructed nano-materials which have collective benefit in food and health care.

- The effect of nano nutraceuticals/functional foods on a particular gene and protein expression can be taken as a challenging task.

\section{References}

1. Kumari A, Singla R, Guliani A, Yadav SK (2014) Nanoencapsulation for drug delivery. EXCLI J 13: 265-286.

2. Kumari A, Yadav SK (2014) Nanotechnology in agri-food sector. Crit Rev Food Sci Nutr 53: 975-984.

3. Kumar V, Guleria P, Kumar V, Yadav SK (2013) Gold nanoparticle exposure induces growth and yield enhancement in Arabidopsis thaliana. Sci Total Environ 461-462: 462-468.

4. Torney F, Trewyn BG, Lin VSY, Wang K (2007) Mesoporous silica nanoparticles deliver DNA and chemicals into plants. Nat Nanotechnol 2: 295-300.

5. Kumari A, Kumar V, Yadav SK (2012) Nanotechnology: A tool to enhance therapeutic values of natural plant products. Trends in Medical Research 7: 34-42.

6. Kumar V, Kumari A, Kumar D, Yadav SK (2014) Biosurfactant stabilized anticancer biomolecule-loaded poly (D,L-lactide) nanoparticles. Colloids and Surfaces B: Biointerfaces 117: 505-511.

7. Kumari A, Kumar V, Yadav SK (2012) Plant extract synthesized PLA nanoparticles for controlled and sustained release of quercetin: A green approach. PLoS ONE 7: e41230.
8. Kumari A, Yadav SK, Pakade YB, Kumar V, Singh B (2010) Nanoencapsulation and characterization of Albizia chinensis isolated antioxidant quercitrin on PLA nanoparticles. Colloids Surf B Biointerfaces 82: 224-232.

9. Yadav SV, Yadav SK, Sood A, Sharma M, Singh B (2011) Development of antidiabetic nanomedicine from stevioside. J Biomed Nanotechnol 7: 54-55.

10. Yadav R, Kumar D, Kumari A, Yadav SK (2014) Encapsulation of podophyllotoxin and etoposide in biodegradable poly-D,L-lactide nanoparticles improved their anticancer activity. J Microencapsul 31: 211-219.

11. Yadav R, Kumar D, Kumari A, Yadav SK (2014) Encapsulation of catechin and epicatechin on BSA NPs improved their stability and antioxidant potential. EXCLI J 13: 331-346.

12. Kumar V, Yadav SK (2013) Influence of physiochemical factors on size of gold nanoparticles synthesised using leaf extract of Syzygium cumini. JCST 2: 104-107.

13. Kumar V, Yadav SK (2011) Synthesis of stable, polyshaped silver and gold nanoparticles using leaf extract of Lonicera japonica L. Int J Green Nanotechnol 3: 281-291.

14. Kumar V, Yadav. SK (2011) Synthesis of variable shaped gold nanoparticles in one solution using leaf extract of Bauhinia variegate $\mathrm{L}$. Digest J Nanomater Biostruct 6: 1685-1693.

15. Kumar V, Yadav SK (2011) Characterization of gold nanoparticles synthesized by leaf and seed extract of Syzygium cumini L. J Exp Nanosci 7: 440-451.

16. Kumar V, Yadav SC, Yadav SK (2010) Syzygium cumini leaf and seed extract mediated biosynthesis of silver nanoparticles and their characterization. J Chem Technol Biotechnol 85: 1301-1309. 